\title{
Sweat and Hair: Online Interventions for Improving Physical Activity in African-American Women
}

\author{
Kayla H. Felix Brianna De Souza Laura N. Uwakwe Jacob Subash \\ Amy J. McMichael \\ Department of Dermatology, Wake Forest School of Medicine, Winston-Salem, NC, USA
}

\section{Keywords}

Hair and scalp disorders · Hair loss · Hair care · Hair styles ·

Exercise $\cdot$ Physical activity

\section{Abstract}

Objective: To evaluate the efficacy of an informational website in improving patient knowledge on hair care and exercise. Design: Pre- and post-exposure surveys, focusing on exercise and hair care practices, were administered to subjects after $1 \mathrm{~h}$ of browsing a dermatologist-designed hair care and exercise website. Setting: Winston Salem State University, a historically Black university in North Carolina, USA. Participants: 22 African-American women (AAW) aged between 18 and 54 years. Measurements: The outcome measures of the study include patient demographics, hair care practices, knowledge of hair/care disorders, exercise habits, and website feedback. Results: There were 22 women enrolled in the study with $95 \%$ identifying as African-American. The average age was $28 \pm 12$ years. A total of $80 \%(16 / 20)$ of subjects reported exercising less than 150 min per week, and $36 \%$ of these patients reported modifying their hairstyle to accommodate physical activity. $85 \%$ learned new informa- tion about hair and scalp disorders from the educational material on the website, and $81 \%$ had increased understanding of their hair health. $91 \%$ reported that they would return to the website. Conclusion: An informational website can be an effective tool to educate AAW on hair and scalp disease, as well as appropriate hair care practices and fitness goals.

ㄷ) 2020 S. Karger AG, Basel

\section{Introduction}

Obesity rates are disproportionately high in AfricanAmerican women (AAW), with a prevalence of 56.9\% [1]. Several barriers to weight loss have been identified, but one dermatologic barrier unique to $\mathrm{AAW}$ is a concern for preserving hairstyles [2-9]. It has been shown that women who avoided exercise due to hair-related concerns are three times more likely to obtain less than the recommended 150 min of moderate physical activity per week $[9,10]$.

Currently, there is minimal web content that addresses the issue of hair maintenance as it relates to exercise, and a notable lack of reliable information regarding proper

$\begin{aligned} & \text { karger@karger.com } \\ & \text { www.karger.com/sad }\end{aligned}$
Karger ${ }^{\prime /}$

Amy J. McMichael, MD

Department of Dermatology, Wake Forest School of Medicine

1 Medical Center Boulevard

Winston-Salem, NC 27157-1071 (USA)

amcmicha@wakehealth.edu 


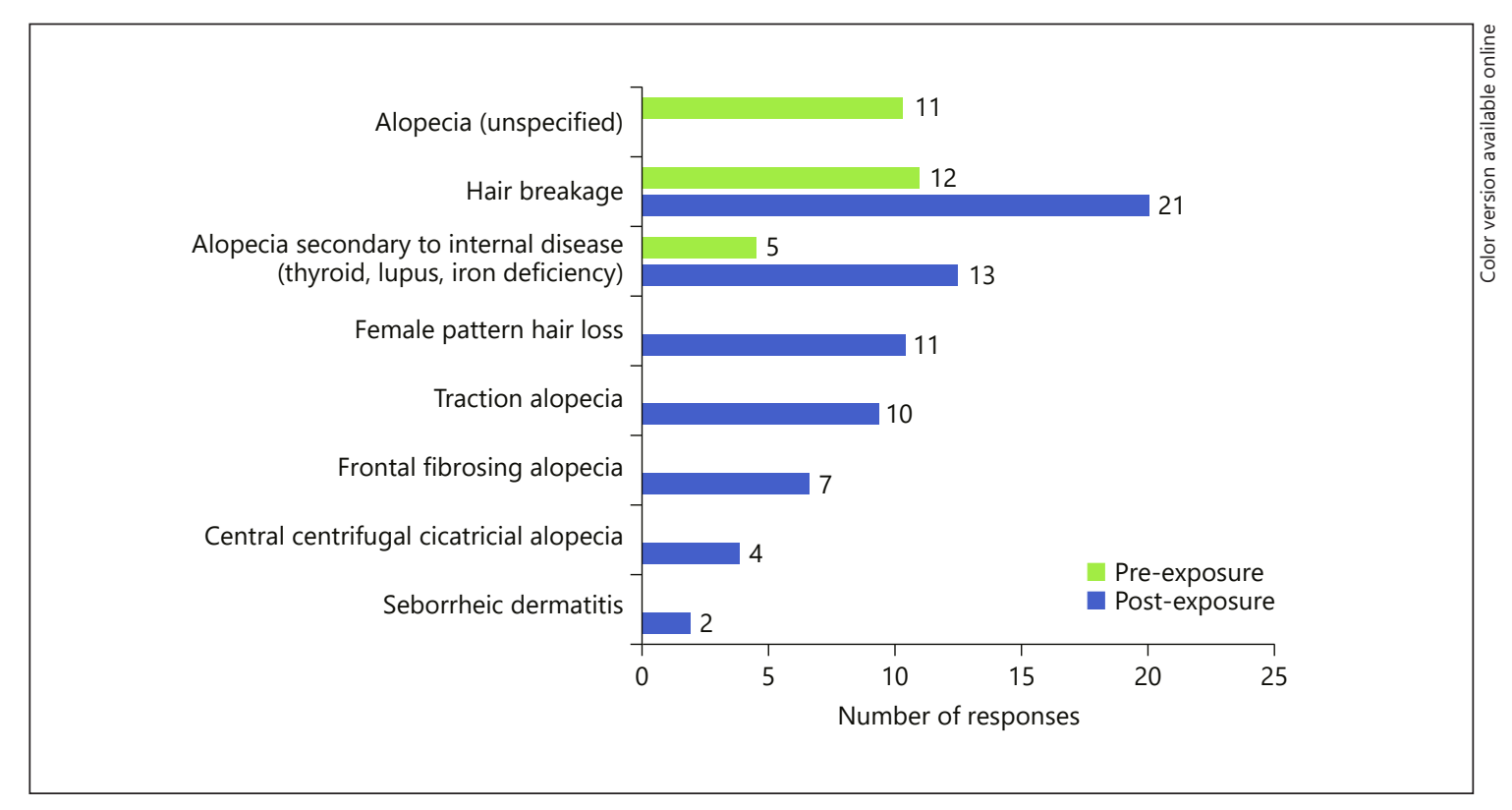

Fig. 1. Awareness of specific hair loss types before and after exposure to the website.

hair and scalp care. Information from dermatologists is primarily located in scientific journals which are not easily accessible to the public. A novel website (www. sweatandhair.com) aimed to address this issue by detailing appropriate hair/scalp care and hairstyle maintenance as it relates to various levels of exercise. In this study, we evaluated the efficacy of the website as an educational tool and identified ways to improve the site's educational offerings.

\section{Material and Methods}

The Sweat and Hair website was designed to include information about common hair and scalp conditions, hairstyling advice, and workout plans. The exercise-conscious styling tips and product suggestions were available for both natural and chemically processed hair. The multimedia exercise content, created by a fitness professional, included workout sessions of various intensities and durations. Patient-friendly explanations of hair/scalp disorders were available, along with a list of common signs and symptoms that may require the intervention of a dermatologist.

AAW between the ages of 18 and 55 years, attending or employed by a historically Black college in Winston Salem, North Carolina, USA, were evaluated. Pre-exposure surveys focused on frequency of exercise, knowledge of hair loss, presence of hair loss, and hair accommodations used during exercise. Each participant then attended a 1-h long demonstration of the website to ensure exposure to all posted material. Following the demonstration, each subject completed a post-exposure survey focused on utility, usability, and understandability of the website and general understanding of hair loss disorders.

\section{Results}

\section{Demographics}

There were 22 women enrolled in the study, aged between 18 and 54 years (mean $28 \pm 12$ ). A total of $95 \%$ of subjects were AAW, and 1 woman (4\%) identified as "other." $77 \%$ were students and the remaining were faculty of a local historically Black college. Of the students, the majority were in their senior year of undergraduate education (45\%).

\section{Hair and Exercise Data Pre-Exposure}

A total of $27 \%(6 / 22)$ of the subjects indicated that they exercised regularly. The remaining responses were "sometimes" $(68 \%)$ or "not at all" (4.5\%). The majority of subjects admitted to exercise either 1 day (36\%) or 2 days (36\%) per week, with the average session being 30-60 $\mathrm{min}$. The subjects reported variable amounts of sweating of the scalp during exercise, including low (27\%), moderate (45\%), and heavy (27\%).

Hairstyle accommodations were reportedly used by $36 \%$ of subjects during exercise: hair weaves/wigs (23\%), followed by natural styles (18\%), and braids/locks (14\%). Methods to preserve hairstyles included hats (45\%), ponytails (41\%), hair wraps/bands (32\%), buns (18\%), and scarves (9\%). Few subjects (18\%) used no accommodations. On a scale ranging from "very upset" $(-2)$ to "very happy" $(+2)$, most subjects were happy with their hair 


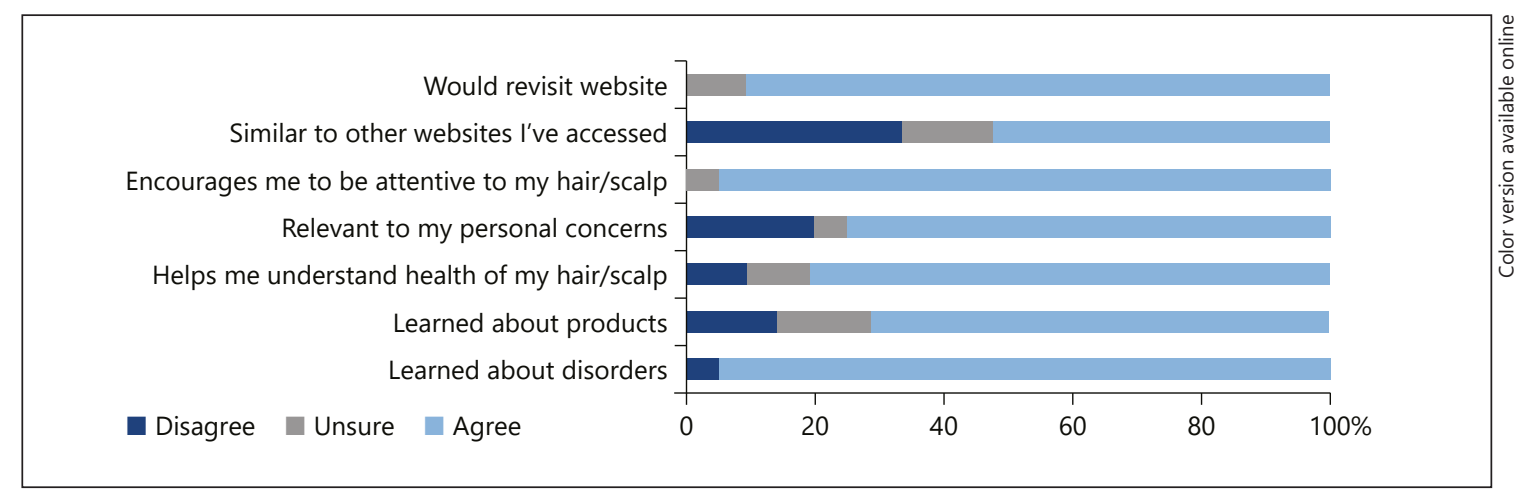

Fig. 2. Feedback on website content.

prior to exercise and were upset with their hair after exercise (Fig. 1).

Hair loss was reported in $45 \%$ of subjects. Of those who reported hair loss, $33 \%$ reported loss from the roots, while $33 \%$ were unsure. Subjects cited hairstylists $(73 \%)$, the Internet $(68 \%)$, and family members $(50 \%)$ as the main source of hair-related information. The majority (64\%) believed that the Internet was an adequate resource for information about hair and scalp health.

\section{Knowledge of Hair/Scalp Disorders}

In the pre-exposure survey, the term "alopecia" was recorded in $50 \%$ of free responses when subjects were asked about potential causes of hair loss. No specific types of alopecia were mentioned. Multiple responders (23\%) cited various traction hairstyles as a cause of hair loss. In the post-exposure survey, there was a noticeable rise in subjects' awareness of the various types of alopecia.

\section{Post-Survey}

Usability of the website was evaluated and rated on a scale as "excellent" (5), "very good" (4)," good" (3), "fair" (2), "poor" (1), or "unsure" (0). Participants evaluated the visual layout (3.62), content (3.29), navigation (3.52), and understandability (3.95). Participant responses for website understandability ranged from "strongly disagree" $(-2)$ to "strongly agree" $(+2)$. Subjects evaluated appropriateness of vocabulary (1.29), usefulness of photos (1.24), frequency of grammatical errors (0.90), and appropriateness of text sizing (1.29). Feedback on website content was positive overall (Fig. 2). The majority of participants (91\%) would revisit the website on their own, and most (75\%) felt it that it addressed their personal concerns and desires.

\section{Discussion}

The primary goals of the Sweat and Hair website were to increase hair care knowledge and to promote physical activity among AAW, regardless of hairstyle. The overall response to the website was positive, with many subjects expressing interest in a website of this nature, and about $50 \%$ of subjects classifying the website as unique. Our results indicate that the website was quite beneficial. After $1 \mathrm{~h}$ of exposure, study participants demonstrated increased awareness of hair loss disorders. One can predict that extended access to the website would lead to a better understanding of hair and scalp disorders, and an awareness of signs/symptoms that warrant medical attention. There were limitations to the study, namely a small sample size and college-aged participants. Using the survey results, the website, currently deactivated, will be redesigned, reactivated, and updated periodically to provide current and culturally relevant content.

The Internet can be a great education tool for disseminating information to patients. In our study, an hour's worth of educational material led to increased awareness of exercise-appropriate hair styles. In addition, subjects demonstrated a more comprehensive understanding of hair/scalp disease(s) and the effect of hair care practices on overall hair health. These findings suggest that patient education would benefit from expansion beyond the clinic walls into the digital space, especially for underrepresented groups such as AAW.

\section{Acknowledgement}

We thank Spencer Hawkins, MD, and Alva Powell for their dedication to helping to build the www.sweatandhair.com website.

Skin Appendage Disord 2020;6:147-150 


\section{Statement of Ethics}

Subjects have given their written informed consent. The study protocol was approved by the Wake Forest University's IRB.

\section{Disclosure Statement}

Amy McMichael is a consultant for Allergan, Aclaris, Pfizer, Galderma, Johnson \& Johnson, Proctor \& Gamble, Samumed, and Incyte, received grants from Proctor \& Gamble and has conducted research for Allergan, Procter \& Gamble, Incyte, Aclaris, and Samumed, and receives royalties from UpToDate. Kayla H. Felix has no conflicts of interest to disclose. Drs. De Souza, Uwakwe, and Subash also have no conflicts to disclose.

\section{Funding Sources}

No funding was received for this study.

\section{Author Contributions}

Study concept and design: Felix, Uwakwe, De Souza, Subash, and McMichael.

Acquisition, analysis, and interpretation of data: Felix, De Souza, Uwakwe, Subash, McMichael. Drafting of the manuscript: Felix, Uwakwe. Critical revision of the manuscript for important intellectual content: De Souza, Uwakwe, McMichael. Statistical analysis: Felix. Obtained funding: Not applicable. Administrative, technical, or material support: McMichael. Study supervision: McMichael.

\section{References}

1 Ogden CL, Carroll MD, Fryar CD, Flegal KM. Prevalence of Obesity Among Adults and Youth: United States, 2011-2014. NCHS Data Brief. 2015 Nov;(219):1-8.

2 Nothwehr F. Attitudes and behaviors related to weight control in two diverse populations. Prev Med. 2004 Oct;39(4):674-80.

3 Horm J, Anderson K. Who in America is trying to lose weight? Ann Intern Med. 1993 Oct; 119(7 Pt 2):672-6.

4 Young DR, He X, Harris J, Mabry I. Environmental, policy, and cultural factors related to physical activity in well-educated urban African American women. Women Health. 2002; 36(2):29-41.
5 Atlantis E, Barnes EH, Ball K. Weight status and perception barriers to healthy physical activity and diet behavior. Int J Obes. 2008 Feb;32(2):343-52.

6 Sanderson B, Littleton M, Pulley L. Environmental, policy, and cultural factors related to physical activity among rural, African American women. Women Health. 2002;36(2):7590.

7 Assari S, Moghani Lankarani M, Caldwell $\mathrm{CH}$, Zimmerman MA. Fear of Neighborhood Violence During Adolescence Predicts Development of Obesity a Decade Later: Gender Differences Among African Americans. Arch Trauma Res. 2016 May;5(2):e31475.
8 Woolford SJ, Woolford-Hunt CJ, Sami A Blake N, Williams DR. No sweat: african American adolescent girls' opinions of hairstyle choices and physical activity. BMC Obes. 2016 Jul;3(1):31.

9 Hall RR, Francis S, Whitt-Glover M, LoftinBell K, Swett K, McMichael AJ. Hair care practices as a barrier to physical activity in African American women. JAMA Dermatol. 2013 Mar;149(3):310-4.

10 US Department of Health and Human Services (USDHHS). 2008 Physical Activity Guidelines for Americans. Washington (DC): USDHHS; 2008. 